\title{
Comparing the Effectiveness of Face-to-Face and Online Training on Teacher Knowledge and Confidence
}

\author{
Lakshmi Sankar \\ Exceptional Education, \\ Troup County School System, \\ Lagrange, GA, USA
}

laksan55@yahoo.com

\author{
Chetan S. Sankar \\ Department of Management, \\ Auburn University, \\ Auburn, AL, USA
}

sankacs@auburn.edu

\begin{abstract}
The National Staff Development Council determined that high quality teaching requires setting forth ambitious goals for students and educators and making significant changes to the existing curriculum, instruction, assessment, and leadership practices. The Council suggested that this could be achieved through intense, well-designed professional learning that provides support to teachers and focuses on learning goals for students, teachers, and administrators. Furthermore, the No Child Left Behind Act directed school districts to provide teachers with an ongoing and targeted high quality professional development that focuses on teaching and learning. Information technology plays a critical role in making online training affordable and accessible.
\end{abstract}

Given the importance of this issue, this study examined the effects of two formats of professional learning, face-to-face and online training, on teacher knowledge and confidence to co-teach. Sixty middle and high school general education and special education teachers from a semi-urban county received training on the six models of co-teaching, teacher roles and responsibilities, and teaming strategies. Quantitative data were collected using pre and posttests of knowledge and confidence and qualitative data were obtained using open ended questions and discussions. Results of the study indicated: (1) both face-to-face and online training significantly increased teacher knowledge to co-teach, (2) there was no significant difference in teacher knowledge between the two formats, (3) face-to-face training significantly increased teacher confidence, but online training did not increase confidence, and (4) there was a significant difference in teacher confidence to co-teach between the face-to-face and online training format.

These results have important implications for educators, developers of curriculum, and administrators of face-to-face and online training programs. These are discussed further in the paper.

Material published as part of this publication, either on-line or in print, is copyrighted by the Informing Science Institute. Permission to make digital or paper copy of part or all of these works for personal or classroom use is granted without fee provided that the copies are not made or distributed for profit or commercial advantage AND that copies 1) bear this notice in full and 2) give the full citation on the first page. It is permissible to abstract these works so long as credit is given. To copy in all other cases or to republish or to post on a server or to redistribute to lists requires specific permission and payment of a fee. Contact 0HPublisher@InformingScience.org to request redistribution permission.
Keywords: online, face-to-face training, self efficacy, knowledge

\section{Introduction}

The National Staff Development Council (2001) determined that high quality teaching requires setting forth ambitious goals for students and educators and making significant changes to the existing curriculum, instruction, assessment, and leadership practices. The Council 
suggested that this could be achieved through intense, well-designed professional learning that provides support to teachers and focuses on learning goals for students, teachers, and administrators.

The most commonly used professional learning method is through workshops or face-to-face training (Gonzalez \& Vodicka, 2008; Kochhar, West, \& Taymans, 1996). Face-to-face training, a traditional professional learning approach offered in large or small groups, provides opportunities for interactions, especially when it is offered in small groups, thus forming closeness in the relationship between the facilitator and the learner (Benson, Johnson, Taylor, Treat, Shinkareva, \& Duncan, 2005). According to researchers, face-to-face communication is the most effective way to deliver instruction because it allows the participants to provide visual cues and verbal feedback as well as communicate via body language. Consequently, the frequent interactions increase the learner's motivation to learn (Daft \& Lengel, 1986).

Recently, there has been a rise in online learning approaches, such as web-based programs and videos, to offer professional learning to teachers (Casey, 2008). The National Center of Education Statistics (2007) reported that during the 2006-2007 academic year, 66 percent of all 2-year and 4 -year institutions offered distance education courses. Distance education programs have become popular to provide continuing education to professionals because it is cost-effective, convenient, and beneficial to teachers' learning and growth (Gonzalez \& Vodicka, 2008; Knackendoffel, 2005; Moller, Foshay, \& Huett, 2008). As school systems and universities are facing severe economic crisis, web-based programs offer the flexibility to reach a wide-range of audience who are separated geographically at the fraction of the cost of campus-based training (Johnson, 2003). But at the same time, researchers have criticized online training to be not as effective as face-to-face training because the teachers who receive online training may not be able to build an affinity with the trainer due to lack verbal and non-verbal feedback and the closeness that can achieved through face-to-face interactions (Mestre, 2006; Richardson \& Swan, 2003).

As expectations for teachers rise and accountability is held as a high priority, professional learning, regardless of the specific format used, drives the school improvement plans of most school systems and 5 to $10 \%$ of the school district budget is allotted for implementing various initiatives (Lowry, 2008). One such initiative that has gained great importance is the way students with disabilities are served in public schools and as a result, school districts are looking for ways and means to address the unique needs of the teachers who serve this population. The No Child Left Behind Act (2002) requires schools to ensure all children have a fair, equal, and significant opportunity to obtain a high-quality education and reach, at a minimum, proficiency on challenging state academic achievement standards and assessments. The law further mandates school systems to close the achievement gap between students with disabilities and their general education peers (Bouck, 2007; Knackendoffell, 2005; Smith \& Leonard, 2005; Zigmond, 2006). The Individuals with Disabilities Education Act (IDEA) of 2004 also mandates that students with disabilities should be educated in the general education classroom as much as possible (Rea \& Connell, 2005; Soodak, 2003).

Research has indicated that professional learning occurs when teachers have the opportunity to study, experiment, and receive specific feedback on the strategies or innovations that lead to improvements in their knowledge, instructional practices, and student learning (Borko, 2004; Fogarty \& Pete, 2007; King \& Newmann, 2000). School systems offer several different types of professional learning, but the most commonly used format is face-to-face training.

The face-to-face training model, frequently referred to as workshops, seminars, presentation, or training program, is held in a group setting, large or small, where the participants engage in frequent and on-going interaction with each other (Brooks-Harris \& Stock-Ward, 1999). Face-toface training is an efficient way to acquaint an audience of a new, unfamiliar theory or plan, spe- 
cifically to teach the basic principles and features of that plan, or to provide information or instruction on a specific topic (Fogarty \& Pete, 2007; Gonzalez \& Vodicka, 2008).

Recently, online training has been identified as a reasonable alternative to face-to-face professional learning in order to maximize the professional learning budget of the local school systems and also to accommodate teachers' busy schedules (Whitehouse, Breit, McCloskey, Ketelhut, \& Dede, 2006). Online learning is a type of distance education program that involves the presence of an institution, which plans curriculum and provides resources and services to students by uniting the teacher with the student electronically (Bruder, 1989; Casey, 2008; Johnson, 2003; Oakley, 2000).

Online learning typically uses the internet to provide instruction, either on-campus or off-campus, totally online, or in a combination of face-to-face and online. Mestre (2006) suggests that online training should include visual and kinesthetic aspects as well as intuition and thinking exercises in order to address the learning needs of the various users. The instruction must have contextually relevant examples so students will be able to apply their learning in real life situations (Willis, 1993). Student attrition in web-based learning is high, and researchers have identified independence, internal locus of control, and computer knowledge, as necessary tools a learner must possess in order to be successful in online learning (Ross, 1996). While developing learning materials, teachers must ensure that they take into consideration the students' background, interests, motivation, and self-efficacy (Willis, 1993).

In order to maximize student learning, educators must offer a consistent and coherent technical framework for students and provide training and support to access technology when needed. Teachers must consider learning preferences of students when selecting technology because students may be more comfortable with one type of technology such as video or audio tools rather than computer-based instruction. It may be desirable to combine various types of technology to reach the interest and ability level of all students (Willis, 1993). Efforts must be taken to ensure that students are provided access to all learning materials and that the geographical separation does not hinder them from having the necessary materials or receiving support (Miller \& King, 2003; Willis). Additionally, online learning similar to traditional methods must incorporate assessment into teaching to measure mastery of student learning (Miller \& King).

As technology is becoming wide-spread, web-based training is seen by higher education institutions and school districts as an efficient, cost-effective way to offer professional learning (Vogel, 2006). But, traditionalists argue that the interactions that occur in face-to-face training is crucial for learning and online learning may not provide the same opportunity (Benson, Johnson, Taylor, Treat, Shinkareva, \& Duncan, 2005).

As the debate continues between these two schools of thought, very little literature is found on the relative merits of a specific professional learning format used to train teachers on the principles of co-teaching and to build teacher confidence to co-teach. Consequently, school systems continue to struggle in identifying a particular cost-effective and time-sensitive format of professional learning that improves teacher knowledge of co-teaching and teacher confidence to co-teach.

The purpose of the study was to determine which form of the two formats of professional learning, face-to-face learning and online learning, increased teacher knowledge of the principles of co-teaching and teacher confidence to co-teach. Teachers who received the traditional format of face-to-face training were compared with those who received online training to examine if there was a significant difference in teachers' knowledge of the models of co-teaching, their roles and responsibilities, and team working strategies. The study further examined which professional learning format significantly increased teacher confidence to co-teach. 


\section{Research Questions}

The study examined the following research questions:

1. Given a prescribed curriculum, does face-to-face training increase teacher knowledge?

2. Given a prescribed curriculum, does online training increase teacher knowledge?

3. Is there a difference in teacher knowledge between the participants in the face-to-face and online formats?

4. Given the prescribed curriculum, does face-to-face training increase teacher confidence?

5. Given a prescribed curriculum, does online training increase teacher confidence?

6. Is there a difference in teacher confidence between the participants in the face-to-face and online formats?

\section{Definition of Terms}

\section{General Education Teachers}

General education teachers were defined as those who are certified to teach the core, content areas of English, math, science, and social studies.

\section{Individualized Education Plan}

It is a plan developed to meet the special learning needs of each student with disabilities. The plan is written and reviewed in collaboration with all service providers, students, and parents and is implemented by the service providers (Vaughn, Bos, \& Schumm, 2000).

Professional Learning, Professional Development, Training

In this study, these three terms were used interchangeably to describe ongoing training that is provided to novice and veteran teachers. The National Staff Development Council (2001) describes professional development as standards-based, data-driven, and job-oriented experience that ensures educators acquire the necessary knowledge and skills to improve student achievement.

\section{Co-teaching}

Co-teaching occurs when a special education teacher and a general education teacher work together in the same classroom, deliver instruction, differentiate the curriculum, manage behaviors, and provide assistance to all students (Cook \& Friend, 1995; Gately \& Gately, 2001; Keefe \& Moore, 2004; Rea \& Connell, 2005).

\section{Self-efficacy}

Self-efficacy is an inner motivational quality that drives the person who possesses certain skills to utilize it to perform a task. Due to self-efficacy the individual has the confidence to translate those skills into actions (Bandura, 1986). In this study self-efficacy and confidence were used interchangeably.

\section{Special Education Teachers}

For the purpose of this study special education teachers were defined as teachers who are certified to teach students with disabilities.

\section{Research Methodology}

The purpose of the study was to determine the impact of two formats of professional learning, face-to-face and online training, on teacher's knowledge of the principles of teaching and teacher confidence. Teachers who received the traditional format of face-to-face training were compared with those who received online training to examine if there was a significant difference in teach- 
er's knowledge of the principles of co-teaching, namely the models of co-teaching, teacher roles and responsibilities, and team working strategies. This research study tested six research questions. The study further examined if the two formats of training increased teacher confidence to co-teach.

The research model is shown in Figure 1. R.Q.1, R.Q.2, R.Q.4, and R.Q.5 were tested to determine if teachers who received face-to-face and online training increased their knowledge and their confidence to co-teach. R.Q.3 and R.Q.6 were tested to determine if there was a difference in the knowledge or confidence to co-teach between the face-to-face and online participants (Figure 1).

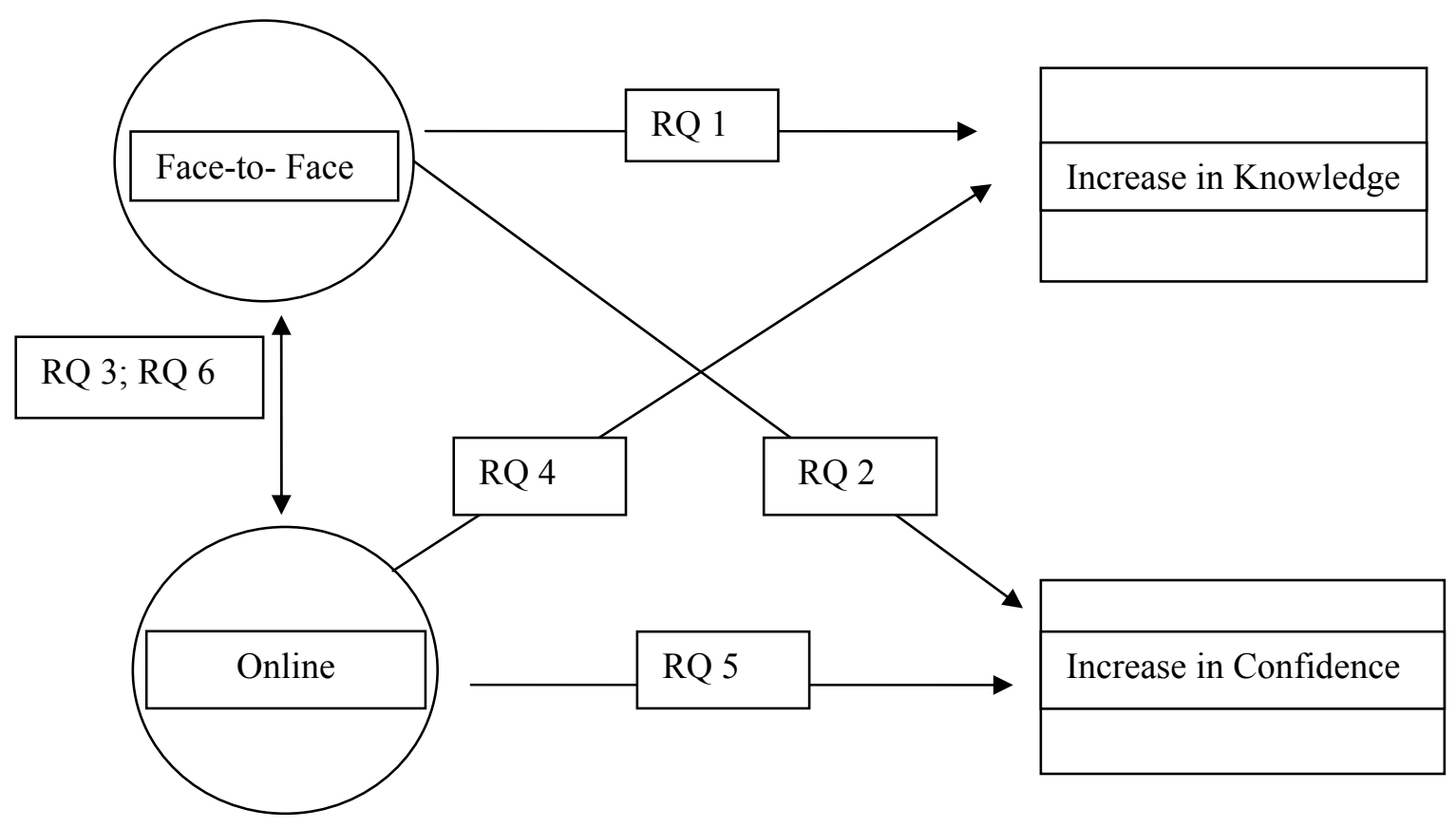

Figure 1: Research Model

\section{Research Design}

The research design that was used in this mixed method, experimental study is Between-Groups ANOVA designs (Garson, 2008).

\section{Independent and Dependent Variables}

The independent variables of the study were face-to-face training and online training and the dependent variables were knowledge and confidence. The treatment that was provided to the subjects was co-teaching training. Pre-tests and posttests were administered to measure the dependent variables and pre-test scores were compared with posttest scores.

\section{Internal Validity of the Research Design}

The combination of the random assignment to treatment and the presence of a pre-test and posttest design served to control sources of internal validity for regression, instrumentation, and mortality. Random assignment controlled for regression factors; pre-test and posttest controlled for instrumentation, and pre-test controlled for mortality. 


\section{Setting and Subjects}

The population for this study was middle and high school co-teachers who taught the core content area of English language arts, math, science, and social studies. All subjects who participated in the study had at the minimum an undergraduate degree and were certified in the area in which they taught.

The setting of the study was a school system located in a semi-urban, lower socio-economic community in south-eastern United States. The subjects of this study were sixty middle and high school teachers, 45 general education and 15 special education teachers, who volunteered to participate in the study. Among the participants 45 teachers were females, and 15 of them were males, and $78 \%$ of them had a graduate degree. The participants had a wide range of teaching experience from less than 5 years to more than 26 years. Altogether 51 teachers had co-taught in one or more classes and most of them were co-teaching at the time the study was being conducted. The racial make-up of the group was varied with 50 Caucasian, nine African-American, and one Asian-American. All teachers were certified in the area they taught.

The sample size using the proportion of approximately 3 general education teachers to 1 special education teacher was selected to replicate the real-life secondary school setting where typically one special education teacher co-teaches with two to three general education teachers.

\section{Instruments}

Two instruments, a test to measure knowledge and a survey to measure confidence, were used to collect quantitative data. Additionally, a third instrument, a satisfaction survey was used to measure the subjects' satisfaction with the training format in which they participated. Qualitative data were collected from four short written responses and teacher discussions during face-to-face and online training.

\section{Knowledge}

A test based on the content from Friend and Cook's co-teaching training materials (2007) was used to measure knowledge. The test consisted of 18 multiple-choice questions, six questions on each topic, namely co-teaching models, teacher roles and responsibilities, and teaming strategies. The content validity of the test had been established by expert judgment of co-teaching trainers who have assessed the test by comparing it with the course content as well as through repeated use of this test in twenty-three different settings and times to measure knowledge of the concepts of co-teaching.

\section{Confidence}

The Expanded skills confidence inventory: Measuring basic dimensions of vocational activity (SCI), a survey, created by Betz, Borgen, Rottinghaus, Paulsen, Halper and Harmon (2003) was used to test teachers' confidence to co-teach. This Likert-type survey consisted of ten items, with a scale of 1 (Not confident at all) to 5 (highly confident). The test-retest reliability and the concurrent validity of the Expanded Skills Confidence Inventory indicated high scores on the reliability and the validity measures.

Two formats of Satisfaction Surveys, one for the face-to-face trainees and another one for the online trainees, were created to determine how satisfied the participants were with the training sessions. Teachers who were trained on face-to-face training also responded to three qualitative questions regarding the training materials. Teachers who received online training responded to four questions regarding the training format. These data were interpreted and analyzed in the results. 


\section{Use of Information Technologies to Enhance Treatment}

The participants were provided two formats of professional learning-face-to-face training and online training- as treatment. All teachers were taught using Friend and Cook's co-teaching curriculum (2007) on the models of co-teaching, roles and responsibilities, and teaming strategies. The use of this curriculum was appropriate for the study because it provided answers for the research questions on teacher knowledge regarding the principles of co-teaching and teacher confidence to co-teach.

Sixty general education and special education teachers were randomly assigned to Group A and Group B. Both groups received the same content, but the mode of delivery was different. Group A received face-to-face training and Group B received online training on co-teaching for eight hours.

Information technology was used to enhance the training experience. The training which incorporated the best practices of professional learning was provided by two trainers. It was contentrich, engaging, collaborative, and interactive and the participants should have an opportunity to study, experiment, and receive feedback (Easton, 2008; King \& Newmann, 2000). Research shows that adult training programs should involve case studies, simulations, problem-solving, and discussions because adult learners like problem-solving approaches and collaboration (Fogarty \& Pete, 2007).

Based on this information, the presentation was interspersed with video clips, audio clips, and discussions. Case studies and simulations were used to further clarify the concepts. The discussions were adapted to suit the mode of the professional learning format. While trainees who received the face-to-face format physically engaged in large and group discussions, the online participants were required to participate in the discussions through a discussion forum and chat room (Goel et al., 2010).

\section{Procedures}

\section{Randomization}

Prior to the study, sample was determined using a purposive sampling method. A proportional stratified random sampling method was used to assign teachers to the treatment (Gay, Mills, \& Airasian, 2006). A total number of sixty participants, 31 in Group A and 29 in Group B, completed the training.

\section{Baseline}

Pretests were administered two days before the treatment. Teachers were instructed to take the test based on their existing knowledge and without using any reference materials or consulting with anyone else. Tests were administered using a paper and pencil for those who received faceto-face training and online for those who received online training.

\section{Intervention}

Face-to-face training. During the first week of intervention, Group A received face-to-face training administered by two trainers in a large group at a training facility. Teachers were divided by the subjects they taught and were instructed to sit in teams of four to six participants in a combination of general educators and special educators. Teachers stayed with their team throughout the day and completed all group assignments with team members. 
The training was divided into three sections; each section lasted for ninety minutes, with 60 minutes of instruction, 20 minutes for discussion, and 10 minutes to complete short assignments related to the topic of instruction.

Online training. In the second week Group B received online training as treatment. Two days prior to receiving online training, Group B was sent written instructions on how to login and access materials on the website, as well as the participants' user names and passwords. Teachers were encouraged to e-mail or call the researcher if they had difficulty accessing the materials. Similar to the face-to-face training, during that session, teachers were assigned to teams for the group project that was completed during co-teaching training and written and oral instructions about the group project were also provided. Teams were divided by the subject area they taught, so team size varied from four to seven depending on the number of teachers who taught the subject. All teams had three to five general education teachers and at least one special education teacher.

Online training used the same content and followed the same structure of the face-to-face training in reference to the content. But, online training was not team taught and the delivery was mainly through the power point presentation and video clips. Teachers had the flexibility to access the materials at their convenience. Teachers in Group B communicated and engaged in discussions with the instructor via e-mail, discussion forum, chat room, or phone to ask questions or clarify issues. Research has pointed out that student attrition could be a problem in distance learning classes and one way to retain students is to provide interventions in the form of short motivational messages (Kellar, 1987b; Ross, 1996; Simpson, 2004). Using this strategy, short messages were sent by the researcher to the participants to encourage them to complete the coursework.

The posttest was made available to participants the day after the training was completed. The test of knowledge and confidence used in the pretest were administered as posttests. Similar to the pre-tests, posttests were completed by participants in the face-to-face training using paper-andpencil and online by the participants in the online training. Paper and pencil tests were asked to be returned in sealed envelopes that were collected on the next day. Tests were scored to determine the mean score of each participant and both groups on the co-teaching test of knowledge and the confidence survey. Additionally, both groups completed a Satisfaction Survey to indicate how satisfied they were with the training format. Table 1 describes the time frame of the study.

Table 1: Time frame of the Study

\begin{tabular}{lll}
\hline Time Frame & Group A & Group B \\
\hline A week prior to the study & $\begin{array}{l}\text { Samples identified and groups } \\
\text { formed }\end{array}$ & $\begin{array}{l}\text { Samples identified and groups } \\
\text { formed }\end{array}$ \\
$\begin{array}{l}\text { 2 days before Face-to-face in- } \\
\text { tervention }\end{array}$ & $\begin{array}{l}\text { Pre-test } \\
\text { Week 1 }\end{array}$ & $\begin{array}{l}\text { Intervention } \\
2 \text { days after intervention }\end{array}$ \\
$\begin{array}{l}\text { Posttest } \\
\text { dions before online interven- }\end{array}$ & & $\begin{array}{l}\text { Instruction on how to use the } \\
\text { online program; password and } \\
\text { login provided ; pre-tests }\end{array}$ \\
Week 2 & $\begin{array}{l}\text { Intervention } \\
2 \text { days after intervention }\end{array}$ & \begin{tabular}{l} 
Posttest \\
\hline
\end{tabular}
\end{tabular}




\section{Analysis Methods}

The test of knowledge provided quantitative data on subjects' understanding of the principles of co-teaching. Each question was individually scored and the mean score for each participant was acquired. Similarly, each item on the test of confidence was individually scored and the mean score of each participant was obtained. Additionally, the mean scores of Group A and Group B were obtained for both tests. The results from each test were compared with the pretest scores.

Free response questions and discussions were analyzed by looking for specific patterns. Qualitative data enriched the quantitative data and extended the understanding of the key concepts and strategies.

\section{Results on Knowledge Acquisition}

The purpose of this experiment was to determine which of the two formats of professional learning, face-to-face and online training, had a greater impact on teacher knowledge of the models of co-teaching and on teacher confidence to co-teach.

Data indicated that teachers who received face-to-face and online training showed an increase in their knowledge of co-teaching. Teacher confidence increased significantly among the face-toface participants, but did not significantly increase among the online participants. All statistical data were analyzed using the SPSS version 12.0 with a preset alpha of .01 or .05.T-tests were run to answer research questions 1, 2, 4, and 5. An ANOVA was run to answer research questions 3 and 6. Qualitative data were analyzed by identifying themes and by coding the data.

\section{Research Question 1: Increase of Knowledge by Face-to-Face Training}

Research question 1 was analyzed to determine if the treatment had any impact on teacher's knowledge of co-teaching. A t-test for non-independent samples set at the conservative alpha of .01 determined that there was a significant increase in teacher knowledge of co-teaching in the face-to-face format. Table 2 describes the results obtained from a paired samples t-test.

Table 2: Results of the Co-teaching Test of Knowledge- Face-to-Face Format

\begin{tabular}{|c|c|c|c|c|c|c|c|}
\hline Variables & Mean & $\mathrm{D}$ & SEM & $\begin{array}{l}\text { 99\%Confidence } \\
\text { of Difference } \\
\text { Lower Upper }\end{array}$ & $\mathrm{t}$ & f & $\begin{array}{l}\text { Sig (2- } \\
\text { tailed) }\end{array}$ \\
\hline Pre-test & 13.19 & 2.6 & .47 & & & & \\
\hline Posttest & 16.29 & 1.16 & .21 & & & & \\
\hline $\begin{array}{l}\text { Post-pre } \\
\text { Difference }\end{array}$ & 3.1 & 2.71 & .49 & 4.44 & 6.36 & 30 & .000 \\
\hline
\end{tabular}

The mean score increased by 3.1 points between pre and posttest and the difference between the pre and post scores existed at the .000 significance level and the standard deviation showed that the scores were close together. Three specific categories of co-teaching- models, roles and responsibilities, and teaming strategies- were examined. Data indicated a statistically significant increase in scores in all three categories between pre and posttest at the preset alpha of .01. The mean scores between the pre and posttest increased in all three categories of co-teaching with the highest gain in the mean scores in the teaming strategies and the lowest in the co-teaching models. Table 3 displays the results of the t-test scores for the participants who received the face-toface training. 
Table 3: Difference between Pre and Post scores of the Three Categories of Co-teaching Face-to-Face

\begin{tabular}{|c|c|c|c|c|c|c|c|c|}
\hline \multirow[t]{2}{*}{ Variables } & \multirow[t]{2}{*}{ Mean } & \multirow[t]{2}{*}{ D } & \multirow[t]{2}{*}{ SEM } & \multicolumn{2}{|c|}{$\begin{array}{l}\text { 99\%Confidence of } \\
\text { Difference }\end{array}$} & \multirow[t]{2}{*}{$\mathrm{t}$} & \multirow[t]{2}{*}{ f } & \multirow[t]{2}{*}{$\begin{array}{l}\text { Sig (2- } \\
\text { tailed) }\end{array}$} \\
\hline & & & & Lower & Upper & & & \\
\hline $\begin{array}{l}\text { Post-pre } \\
\text { Models of } \\
\text { Co- } \\
\text { teaching }\end{array}$ & .87 & 1.55 & .28 & .98 & 1.64 & 3.1 & 30 & .004 \\
\hline $\begin{array}{l}\text { Post-pre } \\
\text { Roles and } \\
\text { Respons. }\end{array}$ & 1.03 & 1.02 & .18 & .53 & 1.53 & 5.7 & 30 & .000 \\
\hline $\begin{array}{l}\text { Teaming } \\
\text { Strategies }\end{array}$ & 1.42 & .99 & .18 & .93 & 1.91 & 8.0 & 30 & .000 \\
\hline
\end{tabular}

Eighty-four percent of the teachers stated that they were confident in using the different aspects of co-teaching as a result of the training. As a general education teacher said, "I am more confident in the utilization of the various models. I know now which ones to use. I am going to start using the different models instead of the same one that I was aware of. "Another teacher added:

I am now aware of the several possible models that can be used to utilize both teachers to meet the student needs. We have used team teaching model for most of the year. I am excited about using parallel and alternative models in the future.

Teachers reported that they would be able to use the different models of co-teaching and would be able to team better by collaborating with each other in identifying the various aspects of coteaching because of the new knowledge. One general educator said, "I was unaware of how to truly utilize a co-teacher and what boundaries there were for the interaction".

Teachers believed that their knowledge of teachers' roles and responsibilities had also increased due to face-to-face training. The training provided them the needed skills to define their specific roles in the co-teaching classroom and to delegate responsibilities. One general education teacher reported, "I felt unsure of my role before the training. This has given me knowledge, insight, and confidence to forge ahead."

Participants also indicated that their awareness of teaming and collaborating increased as a result of the training. They believed that the training through interaction, reflection, and experimentation provided them knowledge on how to engage in collaborative planning and resolve conflicts. One special educator reported, "Now I know how to address the problems in the co-teaching class without confrontations."

Additionally, participants shared their thoughts regarding teaming by providing various strategies and ideas to improve it. They acknowledged that co-teachers must have "chemistry" in order for them to succeed. "The best aspect of co-teaching", according to a teacher, "is that when two teachers click, it is a wonderful model and a great asset to the teaching environment. It's like magic." But, many teachers were quick to point out that when the relationship between the two teachers is discordant, it can adversely affect the teachers' and the students' performances. "We need something like E-Harmony.com when we assign co-teachers", suggested one teacher. Another teacher agreed with him, "We need to look at personalities to match. That is the way we can make co-teaching work." The participants discussed the various models of co-teaching they will 
be incorporating in their lessons, defined teacher roles and responsibilities in a co-teaching class, and provided strategies to resolve issues and problems that could arise from implementing coteaching. Face-to-face training significantly increased knowledge, by actively engaging the learner in the learning process through lecture, discussions, and activities that were incorporated into the training and by providing opportunities for the participants to construct knowledge through interaction.

\section{Research Question 2: Increase of Knowledge by Online Training}

Research question 2 was analyzed to determine if the online treatment had a significant impact on teacher's knowledge of co-teaching. A t-test for non-independent samples set at the conservative alpha of .01 determined that there was a significant increase in teacher knowledge of co-teaching in the online format as evident from the pre and posttest scores in the test of knowledge. The mean scores from the pre-test to the posttest increased by 2.14 points and the difference between the pre and the post was highly significant $(\mathrm{p}=.000)$. The standard deviation indicated that the spread of scores were close together. Table 4 describes the results obtained from the paired samples t-test.

Table 4: Results of Co-teaching Test of Knowledge-Online Format

\begin{tabular}{|c|c|c|c|c|c|c|c|}
\hline Variables & Mean & $\mathrm{D}$ & SEM & $\begin{array}{l}\text { 99\%Confidence } \\
\text { of Difference } \\
\text { Lower Upper }\end{array}$ & $\mathrm{t}$ & $\mathrm{f}$ & $\begin{array}{l}\text { Sig (2- } \\
\text { tailed) }\end{array}$ \\
\hline Pre-test & 15.07 & 2.67 & .5 & & & & \\
\hline Posttest & 17.21 & 1.29 & .24 & & & & \\
\hline $\begin{array}{l}\text { Post-pre } \\
\text { Difference }\end{array}$ & 2.14 & 2.4 & .45 & 3.37 & 4.8 & 28 & .000 \\
\hline
\end{tabular}

Additionally, three categories of co-teaching- models of co-teaching, roles and responsibilities, and teaming strategies-were measured. Data indicated a significant gain between the pre and the posttest scores in all three categories. Table 5 describes the results obtained from the paired t-test at the $99 \%$ confidence level.

Table 5: Difference between Pre and Post scores of the Three Categories of Co-teaching Online

\begin{tabular}{|c|c|c|c|c|c|c|c|c|}
\hline Variables & Mean & $\mathrm{D}$ & SEM & \multicolumn{2}{|c|}{$\begin{array}{l}\text { 99\%Confidence of } \\
\text { Difference } \\
\text { Lower Upper }\end{array}$} & $\mathrm{t}$ & $\mathrm{f}$ & $\begin{array}{l}\text { Sig (2- } \\
\text { tailed) }\end{array}$ \\
\hline $\begin{array}{l}\text { Post-pre } \\
\text { Models of } \\
\text { Co- } \\
\text { teaching }\end{array}$ & .86 & 1.16 & .21 & .27 & 1.46 & 4.01 & 28 & .000 \\
\hline $\begin{array}{l}\text { Post-pre } \\
\text { Roles and } \\
\text { Respons. }\end{array}$ & .66 & .72 & .13 & .29 & 1.03 & 4.9 & 28 & .000 \\
\hline $\begin{array}{l}\text { Teaming } \\
\text { Strategies }\end{array}$ & .62 & 1.05 & .19 & .08 & 1.16 & 3.18 & 28 & .004 \\
\hline
\end{tabular}


In the Discussion Board available online, participants openly and frankly discussed various topics such as the advantages of online training, models of co-teaching, teachers' roles in the coteaching classes, issues and concerns regarding planning, grading procedures, and collaboration. One general educator reported online training was effective because it gave everyone an opportunity to speak, even those who were reflective. "I like being able to think about what I am going to say and posting it online gives me more time to think about what others are saying and forming my response," he reported.

A general education teacher commented on co-teaching, "I am looking forward to incorporating a couple of them (models) in the classroom. Station teaching is one that I have already started planning for an activity in the next couple of weeks". Another teacher reported, "I will use different models, depending on the needs of students in a particular course of study. When assessing (the effectiveness of the model) the success or failure of a lesson can be discussed and tried."

Teachers' knowledge of the roles and responsibilities in a co-teaching class also improved as a result of the online training. One teacher reported that she had a better idea of what her role is in a co-teaching class. A second teacher acknowledged the value of the training by remarking, "I did learn a great deal about the various roles each teacher performs in a co-teaching class." Teachers also recognized that if the responsibilities are not shared there could be an imbalance in power and the students may not view the person with less responsibility as a "real teacher." A general education teacher remarked about the training:

The specific part that has increased is my knowledge of effective co-teaching classrooms and what they should look like and more importantly, the teaching responsibilities section taught me that I do not have to be superman. It is okay to accept responsibility for things that are taught in the classroom, but in my case, I believe that I try to take on so much responsibility, that I would do my job and the next person's job if the opportunity presented itself. However, I have learned that you should collaborate and equally share the responsibilities of the co-teaching classroom.

Furthermore, teacher understanding of teaming strategies increased significantly. Teachers stated that co-teachers must communicate with each other about the roles and responsibilities, their duties in the classroom, their teaching style, and their beliefs about students and learning in order to build an effective team. "A lack of (meaningful) communication can potentially ruin a professional relationship between the co-teachers", said a teacher. Both general and special educators reported that although working with another teacher can sometimes be a challenge, especially when there are disagreements regarding the instruction or instructional practices, it is always a good idea to build collaboration through open and honest communication. "We must be professional and not confrontational", responded a teacher when considering if he and his co-teacher had a difference of opinion. Another teacher reported, "I want to collaborate more with my teachers. I see that it is more important to work closer together than I had realized."

Data conclusively indicated that online training significantly increased teacher knowledge of coteaching.

\section{Research Question 3: Difference in Knowledge Acquisition between Face-to-Face Vs. Online Training}

An ANOVA was run using the traditional alpha of .05 to answer research question 3 . The mean pre-test and posttest scores of Group A were compared with the mean pre-test and posttest scores of Group B. The F statistic for the ANOVA indicated that the mean scores obtained by both groups did not vary significantly and there was no significant difference in the knowledge between the two groups. The result from the ANOVA is described in Table 6. 
Table 6: Comparing the Face-to-Face and Online formats on Knowledge

\begin{tabular}{lllllll}
\hline Variable & Groups & $\begin{array}{l}\text { Sum of } \\
\text { Squares }\end{array}$ & df & $\begin{array}{l}\text { Mean } \\
\text { Square }\end{array}$ & F & Sig \\
\hline Knowledge & $\begin{array}{l}\text { Between } \\
\text { Groups }\end{array}$ & 15.69 & 1 & 15.69 & 2.43 & .12 \\
& $\begin{array}{l}\text { Within } \\
\text { Groups }\end{array}$ & 373.64 & 58 & 6.44 & & \\
& & & & & \\
\hline
\end{tabular}

In the discussion, participants from both groups indicated that their knowledge of the co-teaching models, roles and responsibilities, and teaming increased as a result of the training. Both groups believed that the training provided them considerable knowledge of co-teaching and the roles of both teachers in a co-teaching class. In summary, data indicate definitively that while the participants' scores increased in both formats, there was no difference in the increase of knowledge between the two groups.

\section{Results on Confidence to Co-teach}

Confidence was tested using a survey comprised of 10 items which measured self-efficacy. The construct of the items in the survey was based on earlier research conducted by Betz et al. (2002). Cronbach's Alpha was computed for each variable for both the pre and post survey in order to ensure the items coalesced to represent the construct. The Cronbach's Alpha was well above 0.65, (Table 7) indicating that the items coalesced well in measuring the construct.

Table 7: Internal Reliability for the Confidence Instrument

\begin{tabular}{lll}
\hline Test & Cronbach's Alpha & N of Items \\
\hline Pre Survey & .91 & 10 \\
Post Survey & .91 & 10 \\
\hline
\end{tabular}

\section{Research Question 4: Increase in Confidence by Face-to-Face Training}

Research question 4 was answered by analyzing the data using a t-test for non-independent samples set at the conservative alpha of.01. The results indicated that there was a significant increase in teacher confidence to co-teach among the face-to-face participants as evident from the pre and posttest scores. The mean scores from the pre-test to the posttest increased by 4.7 points and the difference between the pre and the post tests existed at the .000 significance level. Table 8 describes the results obtained from the paired t-test at the $99 \%$ confidence level. 
Table 8: Results from the Confidence Survey- Face-to-face

\begin{tabular}{|c|c|c|c|c|c|c|c|c|}
\hline \multirow[t]{2}{*}{ Variables } & \multirow[t]{2}{*}{ Mean } & \multirow[t]{2}{*}{ D } & \multirow[t]{2}{*}{ SEM } & \multirow{2}{*}{\multicolumn{2}{|c|}{$\begin{array}{l}99 \% \text { Confidence } \\
\text { of Difference } \\
\text { Lower Upper }\end{array}$}} & \multirow[t]{2}{*}{$\mathrm{t}$} & \multirow[t]{2}{*}{$\mathrm{f}$} & \multirow[t]{2}{*}{$\begin{array}{l}\text { Sig (2- } \\
\text { tailed) }\end{array}$} \\
\hline & & & & & & & & \\
\hline Pre-test & 42.3 & 5.8 & 1.0 & & & & & \\
\hline Posttest & 47.0 & 3.93 & .71 & & & & & \\
\hline $\begin{array}{l}\text { Post-pre } \\
\text { Difference }\end{array}$ & 4.7 & 4.6 & .82 & 2.41 & 6.93 & 5.6 & 30 & .000 \\
\hline
\end{tabular}

Furthermore, in order to understand the effect of the intervention on teacher confidence, data were analyzed by investigating two variables, teacher experience and the number of co-teaching classes they had taught. Specifically, scores obtained by (a) teachers who had 0-5 years of teaching experience were compared with teachers with 6 to 26+ years of experience and (b) teachers who had never co-taught were compared with teachers who had co-taught 1-15 classes.

A t-test for non-independent samples set at the conservative alpha of .01 showed that the variable of years of experience significantly impacted teacher confidence to co-teach $(p=.002)$. Teachers who had less teaching experience showed a significant increase in confidence than teachers who had more teaching experience. Similarly, a t-test for non-independent samples set at the conservative alpha of .01 showed that the variable of number of co-teaching classes taught significantly impacted teacher confidence to co-teach $(\mathrm{p}=.008)$. Teachers who had never co-taught showed a significant increase in confidence than teachers who had previously co-taught.

During the face-to-face session and in the follow-up survey, $93 \%$ of the trainees who received face-to-face training reported that their confidence had improved as a result of the training. Participants also specifically identified the areas - models to use during co-teaching, teacher roles and responsibilities, and conflict resolution- in which their confidence had been built.

One participant remarked about the training, "Yes. My confidence has increased since I know what co-teaching is and can be. I can now talk and plan knowledgeably with a co-teacher." A second teacher reiterated, "(Learning about) the different models of co-teaching increased my confidence level of co-teaching. My perception before the training was that co-teaching was team-teaching." One teacher acknowledged that since face-to-face training offered the opportunity to learn with others, it increased her confidence to co-teach. She declared, "There were many positive experiences shared by teachers who currently co-teach and we saw it modeled effectively during the presentation. I feel that this is something I could do."

\section{Research Question 5: Increase in Confidence by Online Training}

Research question 5 was answered by analyzing the data using a t-test for non-independent samples set at the conservative alpha of .01. The results indicated that there was no increase in teacher confidence to co-teach among the online participants as evident from the pre and posttest scores. The mean scores from the pre-test to the posttest increased only by .76 points, which was not significant. Table 9 describes the results obtained from the paired t-test at the $99 \%$ confidence level. 
Table 9: Online Results from the Confidence Survey

\begin{tabular}{|c|c|c|c|c|c|c|c|c|}
\hline \multirow[t]{2}{*}{ Variables } & \multirow[t]{2}{*}{ Mean } & \multirow[t]{2}{*}{ D } & \multirow[t]{2}{*}{ SEM } & \multirow{2}{*}{\multicolumn{2}{|c|}{$\begin{array}{l}99 \% \text { Confidence } \\
\text { of Difference } \\
\text { Lower Upper }\end{array}$}} & \multirow[t]{2}{*}{$\mathrm{t}$} & \multirow[t]{2}{*}{ df } & \multirow[t]{2}{*}{$\begin{array}{l}\text { Sig (2- } \\
\text { tailed) }\end{array}$} \\
\hline & & & & & & & & \\
\hline Pre-test & 43.93 & 5.3 & .99 & & & & & \\
\hline Posttest & 44.69 & 4.49 & .83 & & & & & \\
\hline $\begin{array}{l}\text { Post-pre } \\
\text { Difference }\end{array}$ & .76 & 5.44 & 1.01 & -2.03 & 3.55 & .75 & 28 & .459 \\
\hline
\end{tabular}

Furthermore, data were analyzed by examining the two variables, teacher experience and the number of co-teaching classes they had taught. Specifically, scores obtained by (a) teachers who had 0-5 years of teaching experience were compared with teachers with 6 to $26+$ years of experience and (b) teachers who had never co-taught were compared with teachers who had co-taught $1-15$ classes.

A t-test for non-independent samples set at the conservative alpha of .01 showed that the variable, teacher's years of experience, did not have a significant impact on teacher confidence to co-teach in an online training format. There was no difference in the confidence level between teachers who had less experience than teachers who had more experience. Similarly, teachers who had never co-taught did not show a substantial increase in confidence than teachers who had cotaught.

The qualitative analysis showed that teacher confidence to co-teach was not significantly impacted by the online format. Seventy-eight percent of the participants' comments attested to an increase in confidence due to the training. Similar to the trainees in the face-to-face format, teachers who received online training also specifically identified areas such as co-teaching models, teacher roles and responsibilities, and collaboration as the areas where their confidence had been built.

One general education teacher stated, "I feel more confident because I know the different types of co-teaching. I understand better what is expected." A special education teacher affirmed that the training has given her confidence to resolve conflicts with her co-teacher.

However, teachers differentiated between their knowledge and their confidence regarding coteaching. "I don't think my confidence has increased any. I do know my knowledge of different methods and models helped me to understand how to utilize both my and my co-teacher's strengths." A special education teacher responded with the following statement:

I don't feel as though I have gained more confidence because of this training. Confidence for me has come with my experience and in my own abilities as a teacher. This often will change if I am in a class where I don't feel comfortable with the content or if the regular (education teacher) doesn't have interest in what I may offer as the ExEd (Exceptional Education) expert.

Data indicated that although online training significantly increased teacher knowledge, it did not significantly increase teacher confidence to co-teach. Additionally, the online format had no effect on teacher confidence when measured on the two variables, the years of experience and the number of co-teaching classes taught, thus affirming the finding that the online format does not significantly increase confidence. 


\section{Research Question 6: Difference in Confidence Level by Training Method}

An ANOVA was run using the traditional alpha of .05 to answer research question 6 . The mean pre-test and posttest scores of the participants who received face-to-face training were compared with the mean pre-test and posttest scores of the participants who received online training. The result from the ANOVA is described in Table 10.

Table 10: Comparing the Face-to-face and Online Participants on Confidence

\begin{tabular}{lllllll}
\hline Variable & Groups & $\begin{array}{l}\text { Sum of } \\
\text { Squares }\end{array}$ & df & $\begin{array}{l}\text { Mean } \\
\text { Square }\end{array}$ & F & Sig \\
\hline Confidence & $\begin{array}{l}\text { Between } \\
\text { Groups }\end{array}$ & 222.59 & 1 & 222.59 & 8.78 & .004 \\
& $\begin{array}{l}\text { Within } \\
\text { Groups }\end{array}$ & 1470.67 & 58 & 25.36 & & \\
& & & & & \\
\hline
\end{tabular}

The $\mathrm{F}$ ratio for the ANOVA indicated that the mean scores obtained by both groups varied significantly and there was a significant difference in confidence between the two groups. The data indicated that the confidence level of Group A was significantly greater than Group B.

The participants' satisfaction with the training program was determined by administering a satisfaction survey. The face-to-face survey consisted of five questions and the online survey consisted of six questions. A total of fifty-nine participants responded to the survey, while one faceto-face trainee did not respond. An ANOVA was run using the traditional alpha of .05 to determine if the participants were more satisfied with the face-to-face or online training format. Teachers' satisfaction was measured by computing the mean difference in scores regarding the training format between the two groups before and after the training. The mean rating of the faceto-face training program was 22.5 out of the maximum possible score of 25 and the mean rating of the online training program was 22.4 out of the maximum possible score of 30 . The $\mathrm{F}$ ratio for the ANOVA indicated that the mean scores obtained by both groups varied significantly and there was a significant difference in satisfaction between the two groups $(\mathrm{p}=000)$. Overall, the data indicated that teachers were more satisfied with the face-to-face format than the online format.

While $93 \%$ of the face-to-face trainees shared that they enjoyed face-to-face professional learning format, only $74 \%$ of the online participants responded favorably to the online mode of instruction. One online participant commented, "I would have liked face-to-face training better. I like to have

discussions with others much more than I do the online talk." Another teacher reported, "I enjoyed the online training, however, I would have rather been in a face-to-face training. It is more personal and input from others would have been more readily and easily available."

\section{Discussion}

Professional learning formats that incorporate the best practices of teaching and learning can significantly increase knowledge. However, it is more difficult to have an impact on the affective domain, especially teacher confidence; therefore, it is essential that the professional learning format includes aspects that provide support, feedback, and encouragement to build learner confidence. While knowledge and confidence are essential for teachers' continued success in the classroom, the effects of professional learning on teacher experience is puzzling and is worth investigating. In the following section the impact of professional learning on teacher knowledge, confidence, and experience are discussed in detail. 
Regardless of the format a well-designed professional development program increases teacher knowledge. A high-quality professional learning must have a content that builds the knowledge base of teachers, must be delivered by a facilitator who is both knowledgeable and personable, and should incorporate a presentation style that keeps the audience interested and motivated to learn the material.

The facilitator plays a significant role in professional development such as face-to-face and online by creating an instructional environment that promotes interaction and provides new knowledge through presentations and discussion. The facilitator motivates the learners to learn the topic by actively engaging them in the learning process through questioning, reflecting, and providing feedback. Case studies are particularly useful to promote active learning because they promote higher order thinking skills and keep learners engaged by bringing the real world issues into the classroom.

The facilitator should also know how to engage the participants in large and small group discussion by leading, promoting, and redirecting discussions during the presentation. It is through these discussions that the facilitator encourages the learners to share their thoughts, seek clarification, solve problems, and review information in a safe and a nurturing setting. Consequently, discussions can transform passive learning of listening to lectures to active learning of constructing knowledge by interacting with the environment (Fetsco \& McClure, 2005).

Additionally, while the facilitators must have a thorough knowledge of the subject matter, is able to impart that knowledge to the participants, it is also crucial that they are personable, i.e., able to relate well with the participants. Personable facilitators communicate effectively, motivate and share with the participants the enthusiasm they possess regarding the subject matter, and invoke a desire in them to learn the material.

While the role of the facilitators has some similarities in the face-to-face and online formats, there are also certain differences in their function in the two formats. Most people are familiar with the lecture format in the face-to-face training, but online training requires learner to be engaged in learner-interface modality in order to receive instruction through lectures. The focus changes from facilitator-directed instruction of the face-to-face format to learner-directed instruction in the online format. Therefore, while in both formats the facilitator should ensure that the presentation appeals to the learner, it is even more important to create an online presentation that is captivating to the learner by interspersing the material with activities, humor, audio and video clips. Perhaps the facilitator can use technologies such as blogs and twitter to interact actively and engage the learners. Further research on the use of interactive technologies on improving learnerdirected instruction would be helpful.

While both face-to-face and online training can be used to disseminate knowledge effectively, one shot face-to-face workshops may not create the personal change because knowledge is gained through inquiry and reflection over time with their peers about their day-to-day issues and problems (Gordon, 2004). In that respect, perhaps online training may be better than the face-to-face format because it allows the learners to learn at their pace and time.

Learners in the online format may stop and start at their will and can absorb the information without being dominated by the thoughts and ideas of either the facilitator or their peers that occurs during the face-to-face training. Participants in the online format can be more self-directed and the power of decision-making, which rests with the facilitator in a face-to-face setting, could be transferred to them in the online format, thus making online learning a better option for learners who are self-directed.

However, there are certain situations where online learning may not be effective such as when the topic of study is very difficult, or when the learner lacks confidence and needs intense support 
and encouragement to complete the course. In those circumstances it is better to have face-to-face training instead of online learning because the facilitator in the face-to-face training can discern the learner's struggles and immediately provide feedback. Additionally, learners may need someone else to guide their learning, if they are not at all knowledgeable about the topic of study because without the guidance of a facilitator the learner might not be able to thoroughly understand the concepts. Similarly, when learners have to master a large amount of content in a limited amount of time they would benefit from the face-to-face training because the facilitator can filter the information and focus on the salient points. Face-to-face training is also beneficial when the learners do not have enough computer skills to access the information in online training.

In summary, both face-to-face and online training can increase teacher knowledge and comprehension. While knowledge and understanding alone are not enough to bring about systemic change, they lay the foundation to build higher order cognitive skills, especially if the training incorporates discussions, case study analysis, reflection, and group work. When teachers increase their knowledge and understanding related to teaching and learning they can create a classroom environment that fosters student achievement.

Confidence is increased by face-to-face training and not by online training. Confidence is central to develop higher order cognitive skills so teachers can apply new learning to effect change in their classrooms. Therefore, when school systems plan professional learning activities, they need to not only identify ways to increase teacher knowledge, but also determine methods by which teacher confidence can be increased. One such method is to provide training using the face-toface format because it significantly builds teacher confidence to apply new teaching methodology such as co-teaching. Confidence is built in a community as learners receive support from the facilitator and the other participants through concepts such as social comparison and verbal and non-verbal feedback, which can be easily incorporated into face-to-face training, but not in online training.

First, face-to-face training makes social comparison, judging oneself with the other learners in the environment, possible. Due to reciprocal and group learning, learners are able to observe, model, and compare themselves with others and gain confidence. For example, small and large group presentations in the face-to-face format provide a platform for the participants to observe and model others, and gain confidence to express their opinions and thoughts. However, in the online format, due to the lack of the physical presence of a facilitator and other participants, there is no opportunity for the learners to observe and learn from others, thus, they are unable to build confidence. Unless the online learning environment is well connected with a social support group that uses online interactions for example, e-mail, chat sessions, and discussions, it could become a solitary learning experience and may prevent learners from gaining confidence through imitation and observation.

Additionally, in the face-to-face training the participants have the opportunity to observe and experience real-life demonstration of the concepts, and thereby learn and gain confidence from the model through imitation and observation. Though live demonstration is not possible in online training, modeling can be incorporated into the training through the use of video clips. While creating these video clips, it may be necessary that the person who is modeling the performance activity is familiar to the participants. When the modeling is done by unfamiliar persons, it is possible for the learners to be disengaged from the learning process since they may not be able to relate and learn from that experience. Further research on the use of video technology during online presentation will provide guidance on how to effectively incorporate the video elements in the online format.

Secondly, face-to-face training provides opportunities for feedback and encouragement and motivates the learner who is afraid to attempt a task due to past failures to persist and finish the task. 
In the face-to-face training, the facilitator and the other learners provide instant and constant feedback to support and guide learners during task performance as they attempt new tasks. The facilitator also clarifies misconceptions or misinformation instantly and stops the learners from getting frustrated as they quickly modify their learning and build upon it. As a result of on-going informative feedback, learners obtain confidence to explore unchartered territories, persist despite trials and tribulations, endure failures and ultimately experience success, thereby gain more confidence to attempt even more challenging tasks.

Although online training promotes interaction through discussion forums, the feedback received through the discussion forums is not immediate as in face-to-face interaction. Due to these delayed responses, as learners engage in performance activities, they might encounter failures that could lead to frustrations and disengagement from the activity, which in turn could have an adverse effect on the participant's confidence level. In some situations, the learners in the online format may not even read the postings because of the time lag and consequently may not correct their mistakes. Willis (1993) reported that feedback should be timely and specific in order to motivate learners. One way to address the resulting frustration and dissatisfaction is to use chat rooms, though this will involve losing the unique advantage of asynchronous learning because all learners and the facilitator are logged on to the computers at the same time.

Additionally, the availability of the chat sessions does not always guarantee that teachers would engage in online chatting. Teachers seem to prefer the advantage of having asynchronous learning of online training over the on-going, continuous flow of feedback that the chat room discussions provide. Perhaps because of the various demands placed on them due to the day-to-day operation of school, teachers value flexibility of time and location over the physical proximity of the facilitator or peers. Future research on teacher preferences of professional learning formats and various components that affect the delivery and the reception of professional learning would offer insight into this matter.

Thirdly, non-verbal feedback, the use of gestures, visual cues, and body language to send messages to the listener, is provided by the facilitator and the participants in the face-to-face training in addition to verbal feedback. The facilitator can instantly decipher the participants' reaction, albeit sometimes incorrectly, adapt and adjust the speed and presentation of the material to suit the learner's need, and motivate them. Similarly, the learners also read the subtle messages that the facilitator sends via gestures, body language, verbal and non-verbal cues, and adjust their learning accordingly. As a result, the communication between the two groups becomes more interesting and animated and creates an atmosphere of closeness between them. However, nonverbal interaction is absent in online training. The use of video technology could offset this limitation since videos can be used effectively during online professional development program as the learners will get an opportunity to watch the facilitator use specific strategies and read both the verbal and non-verbal cues of the presenter.

Fourthly, while non-verbal feedback is unique to the face-to-face setting, participants learn information not only through receptive language skills of listening to others speak but also through efficient use of oral language skills. The participants and the facilitator in the online format do not have the opportunity to provide oral responses, communicating with each other only via writing. Written language is more sophisticated than oral communication because it requires specificity and precision in the use of word choice and variety, syntax, and the use of language conventions. It is essential for the learners to choose the right words to express their thoughts, opinions, and ideas, to avoid miscommunication. This could be especially difficult for learners whose written skills are inadequate, so they may use short sentences, cryptic messages, or may not share their thoughts at all. Consequently, they may obtain misinformation or incomplete information, or have miscommunication or no communication at all. Since the learners in the online format have to solely rely on their verbal skills, specifically writing skills, it could limit the social interaction, 
which is essential to build confidence. One way to overcome this problem in the online program is to provide an alternate mode of communication such as video conferences or chat sessions to the participants, where sophisticated use of language is not an essential ingredient for successful communication. However, at this time, the use of video conferences is not possible in the school settings as most schools do not have the resources to buy or use expensive video technology. Though chat sessions can be more easily incorporated into online learning, unless it is closely monitored or required, teachers may not engage in online chats.

Perhaps due to the combination of a lack of confidence-building strategies, inadequate computer skills, and time constraints, attrition is high among learners who participate in the online format. It is essential that support through the use of confidence-enhancing techniques is provided to learners to promote engagement. When learners get frustrated or unmotivated, the facilitators can encourage the learners to complete the task by sending them reminders and positive messages, and by providing them technical and moral support. However, motivational messages and techniques may not always produce desired results because the learners may either ignore the messages or not be inclined to change their minds because they perceive those messages as impersonal due to the physical separation between the participants and the facilitator. When that occurs, it might be beneficial for the facilitator in the online format to make a personal contact with the learner to encourage participation. Additionally, since online learning involves the independent use of technology, the facilitator must ensure that the participants are comfortable using technology, especially if they need sophisticated technical skills. Preparing teachers on how to use technology with ease could prevent frustrations and anxiety that they might experience, while accessing the learning material, which in turn could affect their confidence.

Advocates of online instruction claim that there is no significant difference between face-to-face and online instruction, and that online instruction can be even more effective than the traditional classroom (Johnson, 2003). While it is true with reference to building knowledge, it is not accurate when the focus of instruction is on confidence. Confidence is built through social interaction, verbal and non-verbal feedback, and social comparison and most online professional development programs do not presently offer opportunities for learners to construct knowledge within the social context. In order to build learner confidence, it is essential that online learning should incorporate multi-media components, and provide opportunities for frequent and timely interaction and feedback.

While there was no significant difference in teacher knowledge between novice and experienced teachers, confidence among novice teachers was found significantly greater than experienced teachers in the face-to-face format. However, experience had no impact on the confidence level of teachers who received online training. It is likely that the novice teachers who received the faceto-face training gained confidence from the face-to-face interaction that took place during the training and believed that the knowledge that they had gained at the training had prepared them to implement the strategies, should a co-teaching situation arises. However experienced teachers in either of those formats probably believed that while the training gave them the necessary background information, they need much more than the one day of training that they received. It is possible that they needed additional practice and application before they actually felt confident to apply the skills that they had learned in the training. Since much of these ideas are left to conjecture, future research on identifying the specific needs of experienced and novice teachers will make a significant contribution to the professional learning literature and school improvement activities. 


\section{Limitations of the Study}

The limitations of the study are as follows:

1. The study used a convenience sampling method; therefore, the sample may not be a true representation of all co-teachers. Additionally, by limiting the sample to secondary teachers from a specific geographic location and economic background, generalization of the study to all settings and situations has been restricted.

2. The subjects were randomly assigned to face-to-face training and online training. It is possible that the participants were assigned to the professional learning format that was not their choice or learning style. This could have affected their overall performance in the course.

3. The online course was offered over a period of six days and some participants chose to complete the course during the span of six days, while others chose to complete it during one setting. Participants who completed it one session may have experienced fatigue, which could have affected their performance. Similarly, those who worked on the course material over the six-day time period, could have experienced a disconnect in their learning.

4. The subjects had varied experience levels and knowledge which might have affected their confidence levels and performances. However, through random assignment, this was somewhat controlled.

5. The subjects who participated in the face-to-face and online training program may not have completed the pre-tests and posttests independently, since there was no way to monitor how they took the test. However, there was no reason to believe that they might have consulted with others or referred to the course material as there was no incentive attached to their performance.

6. The study was conducted for a period of three weeks and research indicates that more time is needed to determine the long-term effects of training programs on confidence and performance.

\section{Suggestions for School Improvement}

The passage of The No Child Left Behind Act (2002) has brought professional learning to the forefront by making it the centerpiece of school improvement activities. As school systems work toward meeting this mandate with the limited resources that are available to them, they are frequently confronted with various professional learning formats. Often, school systems implement professional learning formats that are convenient or readily available, but may not meet the individual needs of teachers (Gordon, 2004). Consequently, large amounts of time, money, and resources are wasted as school systems try to implement various professional learning activities to improve schools. In order to address this shortcoming, the study provides the following suggestions regarding professional learning to school systems:

1. If the focus of professional learning is on content acquisition, use an online format since it increases teacher knowledge as significantly as face-to-face and is convenient, cost-effective, and efficient.

2. Use best practices in online training that mirror face-to-face training. Online training should include opportunities for participants to engage in discussions via chat rooms or forums. Technical assistance should be available in case teachers have difficulty with using the technology. The instruction must have contextually relevant examples so teachers will be able to apply their learning in real life. Additionally, teacher attri- 
tion can be a problem with online training, so school systems should take proactive steps to motivate teachers to complete the course work.

3. If online training is used as the sole means of professional learning, school systems should incorporate video conferencing, Podcast, and a combination of at least one or two face-to-face meetings with the online format. Teachers and the facilitator will be able to provide verbal and non-verbal feedback to deepen teacher understanding and build confidence.

4. Provide face-to-face training to build teacher confidence. Teachers need confidence to implement their new learning in the classroom. Confidence should be built by providing opportunities for teachers to engage in reflective dialogue, interaction, and discussions, and through immediate feedback.

5. Build foundational knowledge on a given topic of school reform activity through professional learning before implementing the program school-wide. Knowledge has been defined as the content or the essence of a subject matter.

Teachers must have a comprehensive knowledge of classroom practices that they implement and must have a deep understanding of the principles related to those practices. While mentoring and on-the-job training may help and support teachers in their efforts to implement a best practice such as co-teaching, they may not succeed unless they have firm knowledge of the theory and explanation of that concept. For example, although co-teaching is implemented widely, teachers are not taught the principles and the aspects of the six models of co-teaching. If teachers are expected to participate in co-teaching, then they should be thoroughly acquainted with the six models of co-teaching and the factors that govern the successful implementation of each of those models. This knowledge will help teachers decide on the application of the model in their specific situations.

\section{Suggestions to Developers of Online Curriculum}

Information technology professionals play a strong role in developing online curriculum (Noll and Wilkins, 2002; Bouslama, et al., 2003). The results show that the online curriculum might not make the participants confident about implementing the knowledge that they had acquired. It is therefore essential that they consider newer techniques such as games and simulation to make the participants feel that they are interacting with an instructor. The developers might be able to use the lessons learned by gaming experts who simulate a human being in games. Many of these games, such as Wii, have found a broad based appeal since they mimic a person and seem to induce confidence in the audience. Similarly, the developers of online curriculum might need to simulate the characteristics of the humans delivering the curriculum and incorporate it in the training modules. This will also require a substantial financial investment and acquisition of new skills by IT developers.

\section{Conclusions}

Professional learning is essential to change existing practices and discard ineffective teaching methods. Today, more than ever, as our society is becoming more diverse and there is a strong need to produce a student body ready to compete in this global economy, the need for better prepared teachers becomes central to school reform activities.

Therefore, thoughtful consideration should be exercised in the selection of the professional learning format based on the content and purpose, but school systems choose formats based on convenience, cost effectiveness, and efficiency. Consequently, even though vast amounts of money are spent on training teachers, they do not necessarily make an impact on changing teacher practices. In order to make changes in teachers' practices, it is necessary that school systems identify 
system and school needs and provide professional learning using the format that is most appropriate for the topic of study. It may be worthwhile for school systems to collaborate with teachers and create a structure, which allows them to identify their strengths and needs, and reach out to others for professional learning and support. In addition, online curriculum developers might need to use newer technologies such as games, in order to increase the confidence of the participants that they are acquiring valuable skills.

\section{References}

Bandura, A. (1986). Social foundations of thought and action: A social-cognitive theory. Englewood Cliffs, NJ: Prentice Hall.

Benson, A. D., Johnson, S. D., Taylor, G. D., Treat, T., Shinkareva, O. N., \& Duncan, J. (2005). Community college participation in distance learning for career and technical education. Community College Journal of Research and Practice, 29, 369-394.

Betz, N., Borgen, F., Rottinghaus, P., Paulsen, A., Halper, C., \& Harmon, L. (2003). The expanded skills confidence inventory: Measuring basic dimensions of vocational activity. Journal of Vocational Behavior, 62, 76-100.

Borko, H. (2004). Professional development and teacher learning: Mapping the terrain. Educational Researcher, 33(8), 3-15.

Bouck, E. C. (2007). Co-teaching... Not just a textbook term: Implications for practice. Preventing School Failure, 51(2), 46-51.

Bouslama, F., Lansari, A., Al-Rawi, A., \& Abonamah, A. A. (2003). A novel outcome-based educational model and its effect on student learning, curriculum development, and assessment. Journal of Information Technology Education, 2, 203-214. Retrieved from http://www.jite.org/documents/Vol2/v2p203214-22.pdf

Brooks-Harris, J. E., \& Stock-Ward, S. R. (1999). Workshop: Designing and facilitating experiential learning. Thousand Oaks, CA: Sage.

Bruder, I. (1989). Distance learning: What's holding back this boundless delivery system? Electronic Learning, 8(6), 30-35.

Casey, D. M. (2008). A journey to legitimacy: The historical development of distance education through technology. Linking Research and Practice to Improve Learning, 45(7), 52-54.

Cook, L., \& Friend, M. (1995). Co-teaching: Guidelines for creating effective practices. Focus on Exceptional Children, 28(3), 1-16.

Daft, R. L., \& Lengel, R. H. (1986). Organizational information requirements, media richness, and structural design. Management Science, 32, 554-557.

Easton, L. B. (2008). From professional development to professional learning. Phi Delta Kappan, 89, 755761.

Fetsco, T. \& McClure, J. (2005). Educational psychology: An integrated approach to classroom decisions. Boston: Pearson.

Fogarty, R., \& Pete, B. (2007). From staff room to classroom: A guide to planning and coaching professional development. Thousand Oaks, CA: Corwin.

Friend, M., \& Cook, L. M. (2007). Interactions: Collaboration skills for school professionals (5th ed.). Boston: Pearson.

Garson, G. D. (1998). Research designs: Statnotes from North Carolina State University. Retrieved October 22, 2008 from http://faculty.chass.ncsu.edu/garson/PA765/statnote.htm

Gately, S. E., \& Gately, F. J. (2001). Understanding co-teaching components. Teaching Exceptional Children, 33(4), 40-47. 
Gay, L. R., Mills, G. E., \& Airasian, P. (2006). Educational Research: Competencies for analysis and applications. Upper Saddle River, NJ: Pearson

Goel, L., Johnson, N., Junglas, I., \& Ives, B. (2010). Situated learning: Conceptualization and measurement. Decision Sciences Journal of Innovative Education, 8(1): 215-240.

Gonzalez, L., \& Vodicka, D. (2008). Professional learning: New strategies. Leadership, 37(4), 8-12.

Gordon, S. P. (2004). Professional development for school improvement. Boston: Pearson.

Individuals with Disabilities Education Act. (2004). Retrieved September 28, 2008 from http://www.ed.gov/policy/speced/guid/idea/idea2004.html

Johnson, J. L. (2003). Distance education: The complete guide to design, delivery, and improvement. New York: Columbia.

Keefe, E. B., \& Moore, V. (2004). The challenge of co-teaching in inclusive classrooms at the high school level: What the teachers told us. American Secondary Education, 32(3), 77-88.

King, B. K., \& Newmann, F. M. (2000). Will teacher learning advance school goals? Phi Delta Kappan, $81,576-580$.

Knackendoffel, E. A. (2005). Collaborative teaming in the secondary school. Focus on Exceptional Children, 37(5), 1-16.

Kochhar, C. A., West, L. L., \& Taymans, J. M. (1996). Handbook for successful inclusion. Gaithersburg, MD: Aspen.

Lowry, B. (2008). Online versus face-to-face professional development for adult learners: Learning. Paper presented at the annual meeting of the American Association of Colleges for Teacher Education, New Orleans, LA.

Mestre, L. (2006). Accommodating diverse learning styles in an online environment. Reference and User Services Quarterly, 46(2), 27-32.

Miller, T. W., \& King, F. B. (2003). Distance education: Pedagogy and best practices in the new millennium. International Journal of Leadership in Education, 6, 283-297.

Moller, L., Foshay, W. R., \& Huett, J. (2008). The evolution of distance education: Implications for instructional design on the potential of the web. Techtrends: Linking Research and Practice to Improve Learning, 52(3), 70-76.

National Staff Development Council. (2001). Standards for staff development. Oxford, OH.

No Child Left Behind Act (NCLB) of 2002. (2002). Retrieved September 23, 2008, from http://www.ed.gov/policy/elsec/leg/esea02/107-110.pdf

Noll, C. L., \& Wilkins, M., (2002). Critical skills of IS professionals: A model for curriculum development. Journal of Information Technology Education, 1, 143-154. Retrieved from http://www.jite.org/documents/Vol1/v1n3p143-154.pdf

Oakley, B. (2000). Learning effectiveness: An introduction. In J. Bourne (Ed.), Online education: Learning effectiveness and faculty satisfaction. Proceedings of the 1999 Sloan Summer Workshop. Nashville, TN.: ALN Center, Vanderbilt University.

Rea, P. J., \& Connell, J. (2005). Minding the fine points of co-teaching. Principal Leadership, 5, 29-35.

Richardson, J. C., \& Swan, K. (2003). Examining social presence in online courses in relation to students' perceived learning and satisfaction. Journal of Asynchronous Learning Networks, 7(1), 68-88.

Ross, A. R. (1996). The influence of computer communication skills on participation in a computer conferencing course. Journal of Educational Computing Research, 15(1), 37-52.

Smith, R., \& Leonard, P. (2005). Collaboration for inclusion: Practitioner perspectives. Equity and Excellence in Education, 38, 269-279. 
Soodak, L. C. (2003). Classroom management in inclusive settings. Theory into Practice, 42, 327-333.

Vaughn, S., Bos, C. S., \& Schumm, J. S. (2000). Teaching exceptional, diverse, and at-risk students in the general education classroom (2nd ed.). Boston: Allyn \& Bacon.

Vogel, C. (2006). Professional development: Training day. Retrieved September 28, 2008 from http://www.districtadministration.com .

Whitehouse, P. L., Breit, L. A., Mc Closkey, E. M., Ketelhut, D. J., \& Dede, C. (2006). An overview of current findings from empirical research on online teacher professional development. In C. Dede (Ed.), Online professional development for teachers: Emerging models and method (pp. 13-30). Cambridge, MA: Harvard Education.

Willis, B. (1993). Distance education: A practical guide. Englewood Cliffs, NJ: Educational Technology.

Zigmond, N. (2006). Reading and writing in co-taught secondary school social studies classrooms: A reality check. Reading and Writing Quarterly, 22, 249-268.

\section{Biographies}

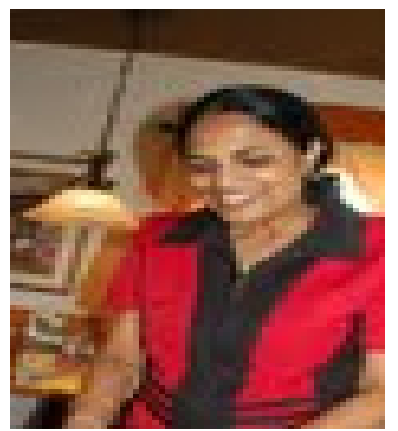

Dr. Lakshmi Sankar is the Director of Exceptional Education at the Troup County School System, Georgia, USA. Before joining this position, she was a special education coordinator and teacher at Fayette County Schools, Auburn City Schools, and other schools in New Jersey and Pennsylvania. She received her Bachelor's and Master's in English from Calcutta and Jadavpur University, India. Then she received a Masters in Special Education from Temple University, Ed.S. in Special Education Leadership and Ed.D. in School Improvement from University of West Georgia, USA. She directs a \$2 million budget for the school district and leads a staff of 120 teachers and 4 coordinators in school and curriculum improvement. She can be contacted at sankarl@troup.org

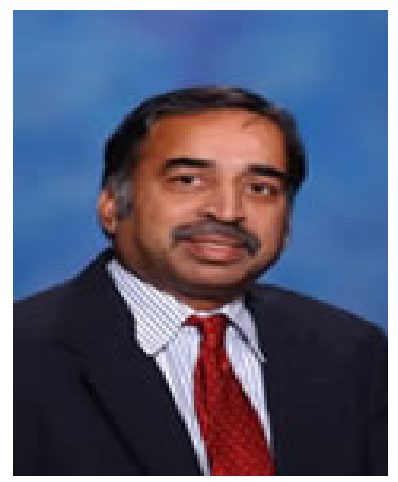

Dr. Chetan S. Sankar is a Professor of Management at Auburn University. He has received more than two million dollars from ten National Science Foundation grants to develop exceptional instructional materials that bring real-world issues into classrooms. He has won awards for research and teaching excellence from the Society for Information Management, NEEDS, Decision Sciences Institute, American Society for Engineering Education, American Society for Mechanical Engineering, International Network for Engineering Education \& Research, and the Project Management Institute. He is the editor-in-chief of the Decision Sciences Journal of Innovative Education and the managing editor of the Journal of STEM Education: Innovations and Research. He can be contacted at sankacs@auburn.edu. 